\title{
UM ATO DE PLENITUDE DIANTE DO VAZIO: SÔNIA BRAGA, O ACONTECIMENTO DISCURSIVO DE AQUARIUS E OS ARQUIVOS DA CONTRACULTURA
}

\author{
AN ACT OF PLENITUDE BEFORE THE EMPTY: \\ SÔNIA BRAGA, THE DISCURSIVE EVENT OF AQUARIUS \\ AND THE ARCHIVES OF COUNTERCULTURE
}

\author{
Pedro Henrique Varoni de CARVALHO ${ }^{1}$ \\ Amanda BRAGA ${ }^{2}$
}

\begin{abstract}
Resumo: Este artigo analisa o retorno de Sônia Braga em Aquarius (2016) enquanto acontecimento discursivo que atualiza a memória de sua trajetória, valendo-se do espelhamento da atriz na personagem que interpreta (Clara), dos espaços de retomada da contracultura, bem como do atual cenário político do país. Neste contexto, o intuito é analisar a emergência de Clara enquanto ruptura, atualização ou, ainda, emancipação de Sônia Braga em relação ao discurso machista que presidiu suas personagens anteriores, fazendo desse retorno não apenas uma aparição artística, mas também um ato político. Para tanto, partiremos do protesto organizado pelo elenco do filme no Festival de Cannes (2016), a fim de demonstrar como há - em Clara e em Sônia Braga, em Aquarius e no Brasil - um jogo entre o micropolítico e o macropolítico: uma resistência que preserva os lugares de memória diante das relações de força estabelecidas pelo capital. Demonstrar-se-á, por fim, como o cinema intimista produzido por Kleber Mendonça, relacionado à banalização da violência cotidiana, apresenta formas de dizibilidade e visibilidade do Brasil, atualizando a cinematografia de interpretação do país, à esteira do Cinema Novo de Glauber Rocha. Para tanto, será adotada uma abordagem discursiva, que faz trabalhar noções de Michel Pêcheux e Michel Foucault em diálogo com a crítica cultural.
\end{abstract}

Palavras-chave: Sônia Braga. Aquarius. Discurso. Contracultura. Micropolítica.

\begin{abstract}
This paper analyzes the return of Sônia Braga in Aquarius (2016) as a discursive event that updates the memory of her trajectory by using her mirroring in the character she plays (Clara), the spaces of resumption of counterculture, as well as the current political scenario of the country. In this context, the aim is to analyze the emergence of Clara as a rupture, update or even an emancipation of Sônia Braga regarding the male chauvinist discourse that presided her previous characters, making this return not only an artistic appearance but also a political act. To do so, we will start with the protest organized by the cast of the film at the Cannes Film Festival (2016), in order to demonstrate how - in Clara and Sônia Braga, in Aquarius and in Brazil - there is a game between the micro-political and the macro-political: a resistance that preserves the places of memory before the relations of force established by the capital. We will demonstrated, lastly, how the intimate cinema produced by Kleber Mendonça, related to the trivialization of daily violence, presents forms of speakability and visibility of Brazil, updating the country's interpretation cinematography, with the Cinema Novo by Glauber Rocha. For that, a discursive approach will be adopted, which makes the notions of Michel Pêcheux and Michel Foucault work in dialogue with cultural criticism.
\end{abstract}

Keywords: Sônia Braga. Aquarius. Discourse. Counterculture. Micropolitics.

\footnotetext{
${ }^{1}$ Possui mestrado e doutorado em Linguística pela UFSCar e é pós-doutorando no Departamento de Informação e Cultura da ECA/USP. Ocupa atualmente a função de diretor editorial do Projor - Instituto para o Desenvolvimento do Jornalismo e é responsável pela edição do portal do Observatório de Imprensa. E-mail: pedro.varoni@hotmail.com.

${ }^{2}$ Professora adjunta do Departamento de Letras Clássicas e Vernáculas da UFPB. Possui graduação em Letras pela UFPB (2006), mestrado em Linguística pela UFSCar (2008) e doutorado em Letras pela UFPB. E-mail: braga.ufpb@hotmail.com.
} 


\section{Introdução}

Em maio de 2016, o elenco de Aquarius (2016), filme dirigido por Kleber Mendonça, chegava ao tapete vermelho do Festival de Cannes para concorrer à Palma de Ouro. Em punho, cartazes denunciavam, a toda imprensa internacional, um iminente golpe de Estado no Brasil (Fig. 1): Brazil is experiencing a coup d'etat; A coup took place in Brazil; Un coup d'etat a eu lieu au Brésil; 54.501.118 votes set on fire. Segundo cobertura do El Pais (2016), tanto o protesto quanto o filme tiveram amplo apoio daqueles que aguardavam o elenco dentro da sala: os mesmos aplausos foram endereçados à denúncia e ao longa-metragem. Sua exibição teria sido aplaudida por 10 minutos, ininterruptamente.

Figura 1 - Elenco de Aquarius durante protesto político no Festival de Cannes.

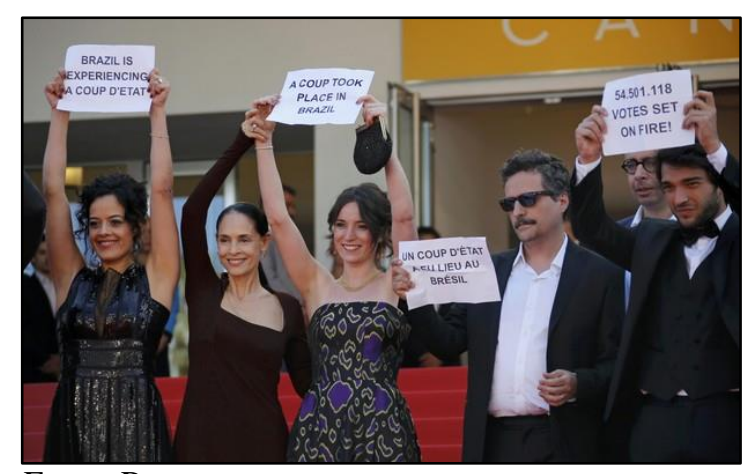

Fonte: Reuters.
Figura 2 - Sônia Braga e elenco de Aquarius no Festival de Cannes.

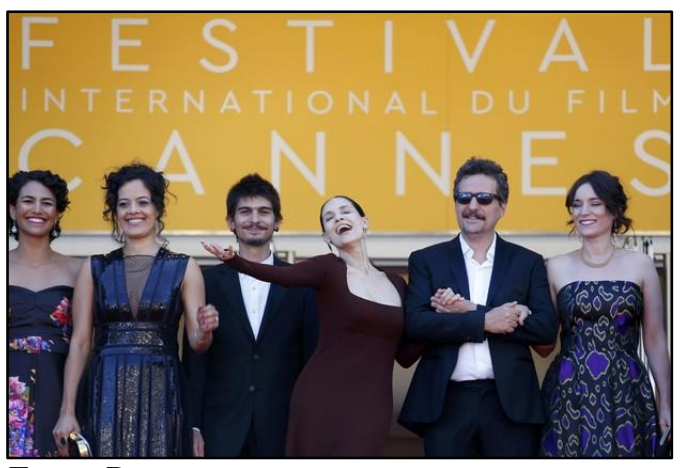

Fonte: Reuters.

Aquarius narra a história de Clara (Sônia Braga, Fig. 2), uma jornalista e escritora de 65 anos, viúva e mãe de três filhos adultos, que mora em Boa Viagem, na cidade de Recife. Seu prédio, o mais antigo à beira mar, é alvo de uma feroz especulação imobiliária: pretende-se construir, em seu lugar, um grande empreendimento. Clara é a última moradora, a única que resiste à investida: "Aquarius é a história de uma mulher que se recusa, ponto. Intransitivamente" (VALEK, 2016, online). Numa espécie de revival de sua trajetória, o filme conta o modo como a personagem vivida por Sônia Braga faz frente à construtora que propõe demolir o prédio em que morou ao longo da vida. Seu apartamento, aos olhos da construtora, é uma espécie de heterotopia: um lugar localizável, efetivo, embora inatingível, "simultaneamente mítico e real" (FOUCAULT, 2003, p. 416). Seu apartamento é aquilo que está fora, além, ainda que constitutivo, ainda que ao alcance das mãos: "as heterotopias supõem sempre um sistema de abertura e fechamento que, simultaneamente, as isola e as 
torna penetráveis" (FOUCAULT, 2003, p. 420). O apartamento de Clara é, enfim, um espaço de memória, impregnado de seu passado e de seu presente: sua vida corre pelos vãos.

Em Clara, toma corpo uma resistência política. A personagem, o filme, são alegorias de um Brasil deteriorado: engolido pela ganância das grandes empresas, pelo crescimento desordenado, por uma conjuntura política, institucional e midiática em crise. A própria Sônia Braga dirá, ainda naquele mês de maio, que "Aquarius é o Brasil. É aquele edifício, com os seus cupins que o vão destruindo lentamente” (FERREIRA, 2017, online). Há em Clara também uma resistência feminista: empoderada diante de uma ameaça autoritária e masculina, a personagem se porta como o próprio fio de Ariadne: é apenas e tão somente a partir dela (de quem a câmera não tira os olhos um segundo sequer) que o conflito se desenvolve e encontra seu desfecho. Entre a política e o feminismo, o diretor não deixará de endossar a comparação feita pela imprensa entre Clara e a então presidenta Dilma Rousseff (a quem o anunciado golpe deporia, meses mais tarde): "São duas mulheres que estão sendo despejadas e precisam lidar com homens corruptos para tentar manter a casa onde vivem" (GOMES, 2017, online).

Entre Clara e Dilma Rousseff, entretanto, haveria, ainda, uma terceira mulher: Sônia Braga. Depois de 20 anos longe dos holofotes, Sônia Braga marcaria seu retorno entre rupturas e atualizações. Seu papel em Aquarius marca uma ruptura entre Clara e as personagens interpretadas em trabalhos anteriores, como Hair (1969-1972), Gabriela (1975), Dona flor e seus dois maridos (1976), Dama do lotação (1978) e Tieta do agreste (1996), nos quais a atriz, tão representativa de nossa construção cultural, estava enredada por um discurso que perpassava questões como a contracultura, a liberdade sexual, a construção de uma mulata brasileira, a sex symbol. Em 1968, durante a montagem brasileira da peça Hair, Sônia Braga causou escândalo ao aparecer nua em cena; é inesquecível a cena em que Gabriela sobe no telhado em busca de uma pipa; no cartaz do filme Dona flor e seus dois maridos, Sônia Braga está nua, na cama, com as pernas cruzadas viradas ao leitor, acompanhada de Vadinho e Teodoro...

À esteira dessa ruptura, é possível pensar na atualização que toma corpo em Clara, tendo em Sônia Braga uma atriz signo do Brasil em diferentes momentos de sua história. A atriz é, em Aquarius, um acontecimento discursivo, entendido por Pêcheux (2008, p. 17) enquanto um "encontro de uma atualidade e uma memória", na medida em que funda uma nova discursividade para seu corpo, para sua carreira, atualizando os discursos que a constroem na medida em que se distancia do componente sexual que anteriormente a enredava. Nesse intuito, tanto a atriz quanto a personagem se fazem valer da maturidade 
oferecida pela idade, de um passado bem sedimentado, bem como do empoderamento que daí derivam. Confundem-se, em certa medida, a personagem e a atriz. Kleber Mendonça chega a dizer para Sônia Braga, em meios às gravações: "sinto-me meio estranho, pois já não sei muito bem se você é a Clara ou a Sônia” (FERREIRA, 2017, online).

Assim, considerando o cenário até aqui exposto, têm-se que a análise da emergência e do acontecimento de Sônia Braga em Aquarius perpassa o entrecruzamento de pontos de deriva que potencializam os sentidos do filme. Como chave de interpretação, a proposta é percorrer os domínios de memória. Neste ensejo, este artigo apresenta-se dividido em dois tópicos. Por um lado, discutir-se-á o lugar representado historicamente pela trajetória da atriz Sônia Braga: seu surgimento como um dos símbolos da contracultura brasileira (tornando-se tradução imagética das personagens de Jorge Amado e Nelson Rodrigues, além de musa de canções de Caetano Veloso), passando pela espécie de autoexílio que a afastava dos riscos de se tornar presa aos estereótipos de si mesma, até sua emergência, atualmente, para as telas de Aquarius, depois de 20 anos sem filmar no Brasil, num espelhamento entre sua trajetória e a trajetória da personagem Clara. Por outro lado, analisar-se-á o lugar representado pelo cinema de Kleber Mendonça como singularidade e ruptura do imaginário construído em outras visões do Nordeste (os quais marcam a trajetória da atriz enquanto sensualidade da mestiçagem tropical), bem como sua filiação, em linhas descontínuas, a certa tradição de interpretações cinematográficas do Brasil, cujo marco é o Cinema Novo.

\section{Sônia Braga em Clara (ou Clara em Sônia Braga): signos da brasilidade perdida}

Os temas da breve cinematografia de Kleber Mendonça tangenciam as questões da política e do real social que aparecem com força no momento do impeachment de Dilma Rousseff, em 2016: o cinismo de uma elite presa aos desígnios do capital globalizado, aliada aos piores defeitos de uma tradição coronelista e patrimonialista; à sociedade machista que quer sempre impor o lugar destinado à mulher, além das causas e efeitos dessas temáticas na vida cotidiana.

Nas obras do Diretor, o ponto de partida é sempre micropolítico. Tanto em $O$ som ao redor (2012) quanto em Aquarius (2016), descortina-se, a partir das relações mais cotidianas, o tema das raízes históricas da violência e da desigualdade na sociedade. Em Aquarius, as

práticas da tradição com verniz moderno - tão bem representada pelo personagem do jovem empreendedor interpretado pelo ator Humberto Carrão - vem para destruir os edifícios, 
queimar os discos, eliminar a história. O lançamento do filme coincide com a tomada do poder de um grupo político que busca impor os desígnios de um discurso de base econômica empreendedora, propondo a eliminação da obrigatoriedade das humanidades no Ensino Médio e retirando do poder, através de manobras político-jurídico-midiáticas, uma mulher eleita democraticamente. Tudo isso se encontra no improvável retorno de Sônia Braga como protagonista do filme de Kleber Mendonça e no acontecimento do protesto em Cannes, acusando o golpe. Jogo entre o real da língua e o real da história (PÊCHEUX, 2008), entre a constituição de diferentes subjetividades presentes na trajetória da atriz e na emergência dessa nova voz no audiovisual brasileiro representada pelo cinema pernambucano.

O primeiro ponto de aproximação entre a narrativa do filme e a trajetória de Sônia Braga está, justamente, na escolha do significante Aquarius, que designa o prédio onde se passa a trama, elemento singular e deslocado do padrão urbanístico da orla de Boa Viagem. O anacronismo do edifício e da única moradora que o habita ecoa a era de aquarius do ideário hippie, marco do surgimento da jovem atriz de teatro, ao final dos anos 1960, na montagem de Hair (1969-1972). O prédio antigo, sem os padrões de segurança exigidos pelas práticas contemporâneas, é apresentado em sua singularidade em meio às modernas construções espelhadas de matriz panóptica, de onde se vê, mas não se é visto (FOUCAULT, 2013). Lá dentro, onde Clara habita, o espaço e a circulação remetem a um passado que se faz presente nos modos de ocupação da personagem. Há um jogo de forças entre o capital moderno transnacional e seu impacto nas subjetividades e o espaço simbólico da resistência, sinalizando certa subjetividade feminina de matriz contracultural de onde emergiu Sônia Braga, no final dos anos 1960, no musical Hair. Esse elo entre a vida real e a protagonista de Aquarius é um dos principais elementos da potência poética narrativa do filme: "Sônia não é Clara, mas Clara também é Sônia" (MENDES, 2017, online), repercute a imprensa portuguesa diante de um interdito de reflexão que paira sobre grande parte do jornalismo brasileiro nesses tempos sombrios ${ }^{3}$.

Os índices da contracultura se encontram no nome do edifício resistente entre os arranha-céus que roubam a brisa, mas também nas canções do toca-discos de Clara: entre rocks ingleses, têm-se Gilberto Gil e a música de encerramento do filme: Hoje, de Taiguara, lançada em 1968: trago em meu corpo as marcas do meu tempo [...] eu não queria a juventude assim perdida. A música no filme não cumpre apenas a função de trilha sonora para

\footnotetext{
3 A expressão foi usada por Raduan Nassar quando da entrega do Prêmio Camões 2016. Disponível em: <http://brasil.elpais.com/brasil/2017/02/17/cultura/1487345056_199380.html>. Acesso em: 31 mar. 2017.
} 
o enredo, as canções se tornam uma espécie de elo entre a narrativa ficcional e uma cartografia histórica da brasilidade. Dizem respeito à trajetória de Sônia Braga ${ }^{4}$ na mesma medida em que dão régua e compasso para o dia-a-dia de Clara, aquela que, preservando seu espaço heterotópico (FOUCAULT, 2003), ancora-o numa temporalidade poética e mítica, em contraposição ao tempo do progresso linear, ou cronométrico, como prefere Octávio Paz (1976): enquanto o segundo supõe uma sucessão vazia e homogênea, o primeiro acha-se impregnado de todas as partículas da existência. Clara não se furta a viver o mundo atual, como mãe, mulher, cidadã, lutando por seus direitos; mas circula pelo Recife contemporâneo sem se objetivar diante de tantas pressões, preservando algo da bandeira micropolítica contracultural que floresceu também nas praias nordestinas a partir de final dos anos 1960 até a década de 1980: o período em que Sônia Braga deixava o país:

\begin{abstract}
A contracultura abria fogo contra a espécie de morte em vida produzida por uma sociedade onde impera o totalitarismo tecnocrático. Sistemas com integração organizacional perfeita e um exército de "especialistas técnicos" para explicar como deve funcionar a vida da política à educação; do lazer à cultura como um todo (DIAS, 2003, p. 75).
\end{abstract}

Aquarius é, assim, metonímia de uma brasilidade ameaçada: a fidelidade aos espaços de memória afetiva, a tradição da canção popular como "tradução" do país, a constituição de uma subjetividade feminina erigida na luta contra os preconceitos, o espaço da poesia e da fruição como elementos vitais do cotidiano em contraponto à lógica competitiva da ordem contemporânea. Todos esses pontos são representados no filme pela relação de Clara com o espaço onde habita. A narrativa do filme se sustenta, como dissemos, entre o embate das forças micropolíticas - representadas pela resistência de Clara a deixar seu espaço vital de memória e sucumbir às normatizações que nos impõe um regime de vida governado pela insegurança e pelo medo - e as macropolíticas - os interesses do capital que não querem deixar pedra sobre pedra desses edifícios simbólicos.

As cenas de aniversário em família, a identificação com a tia de postura libertária, a luta contra o câncer, os caminhos da intelectualidade, são elementos apresentados pela narrativa e que são definidores da subjetividade de Clara, que justificam seu apego ao território onde se deram tais movimentos e parecem imperceptíveis diante da insensibilidade daqueles que a

\footnotetext{
${ }^{4}$ Sônia Braga teria sido a musa inspiradora de Caetano Veloso na canção Trem das cores e também, junto com Zezé Mota e outras da geração dos anos 1970, de Tigresa. Disponível em: <http://blogs.oglobo.globo.com/ancelmo/post/caetano-veloso-tigresa-sou-eu-558458.htm>. Acesso em: 07 abr. 2017.
} 
pressionam: a própria filha, os grandes empreendedores, os grupos políticos. Não há possibilidade de entendimento entre o mundo de Clara e o pragmatismo contemporâneo, mas a compreensão disso, por parte da protagonista, não a faz sucumbir à ordem dominante: ao contrário disto, fortalece sua resistência. Assim como o coronel urbano de $O$ som ao redor, Clara não teme os tubarões da praia de Boa Viagem, mas, ao contrário dele, os enfrenta na luz solar para voltar, em seguida, para seus discos e livros.

Clara representa, em certo sentido, uma subjetividade de emancipação em relação à ordem machista e coronelista encravada no período retratado por Jorge Amado em Gabriela, cravo e canela (1958) ou em Dona flor e seus dois maridos (1966). A interpretação de Sônia Braga na novela Gabriela, em 1975, abriu caminho para uma trajetória de sucesso também no cinema brasileiro, associada a um momento em que se buscava, para além das experimentações estéticas e temáticas de final dos anos 1960, maior expressão de mercado. E a presença de Sônia Braga foi de grande relevância nessa estratégia. Há uma cena antológica da novela protagonizada pela atriz que faz parte do imaginário não só brasileiro, mas também português ${ }^{5}$. Referimo-nos àquela em que a personagem Gabriela sobe no telhado de uma casa de Ilhéus, buscando resgatar a pipa de um garoto. Há ali um jogo entre o machismo que objetifica o corpo da mulher e a representação de Sônia Braga no intermeio entre a ingenuidade e a malícia, resultando numa sensualidade que ecoa a matriz das brincadeiras indígenas. A imagem fala de um país que não existe mais, dando lugar às coreografias de erotização precoce embaladas pela massificação da música de entretenimento fácil guiada pela lógica do mercado.

No imaginário brasileiro, Sônia Braga representa esse espaço simbólico entre a alegria espontânea das brincadeiras indígenas, a sensualidade desprovida do excesso de intervenções (a beleza pura dos versos de Caetano Veloso), a mulher que abriu mão do conforto da estabilidade e, numa repetição de modelos, aquela que estava destinada a se lançar na carreira internacional. Jamais teremos acesso aos motivos tidos por Sônia Braga para trocar o Brasil pelos Estados Unidos no final dos anos 1980, mas podemos tomar como argumentos razoáveis a ambição pela carreira internacional ou a fuga de modos de vida restritivos, a busca de outros horizontes profissionais e existenciais. É razoável supor que a mistura dois fatores

\footnotetext{
${ }^{5}$ Gabriela foi a primeira telenovela brasileira exibida em Portugal, em 1977, ao final do Governo Salazar. Os jornais da época, ao descrevem o fenômeno de popularidade da novela, referiram-se à alta popularidade da novela em terras lusitanas como Gabrielomania (CUNHA, 2003).
} 
explique a partida de Sônia Braga. O contexto acentuava a predominância das leis do mercado reduzindo o espaço de experimentações artísticas e existenciais da juventude contracultural.

A influência dessa cooptação pela sociedade disciplinar do caráter de resistência da subjetividade contracultural gerou, nas palavras de Suely Rolnik (2010, p. 22), uma legião de "zumbis antropofágicos": aqueles que aderiram à flexibilidade da ordem neoliberal, abrindo mão das bandeiras revolucionárias das quais foram protagonistas. Esse momento é o pano de fundo da novela Dancin' Days, de 1978, de Gilberto Braga, em que a atriz vive o papel de uma ex-presidiária - condenada por matar um homem atropelado num assalto a uma loja de lança-perfumes - e, ao sair da prisão, torna-se a estrela de uma discoteca carioca. A temática da novela capta algo dessa transição do ideário hippie contracultural na ordem do espetáculo e do culto às celebridades que ganharia força na década seguinte. "Depois de alguns capítulos fica claro que a máscara de rebeldia dos personagens jovens reveste simplesmente uma mentalidade empreendedora de modernos empresários do capitalismo avançado" (SIMÕES; COSTA; KEHL, 1986, p. 308).

Sônia Braga, desde sempre conectada às dinâmicas do mercado audiovisual, se distancia desse Brasil - indo para o centro do capitalismo ocidental - e reaparece vez ou outra em atuações pontuais, mas permanece como imagem nostálgica nas revisitações das suas cenas e personalidade. A interpretação de Dona Flor no cinema, um ano depois de Gabriela, se tornou um marco de popularidade. O filme de Bruno Barreto foi recordista de público durante 34 anos, sendo ultrapassado por Tropa de elite 2, em 2010. Sônia se torna a mais pura tradução imagética da literatura de Jorge Amado. Há, entretanto, outras brasilidades nas personagens interpretadas por Sônia Braga, como a dona de casa suburbana da Dama do lotação (1978), versão de Neville de Almeida para a obra de Nelson Rodrigues; ou a mulher de um empresário falido de Eu te amo (1981), de Arnaldo Jabor, que lhe rendeu o prêmio de melhor atriz em Gramado, em 1981. Uma trajetória que a torna uma das mais representativas atrizes, ecoando uma brasilidade diversa entre a exuberância tropical do Brasil pré-industrial de Jorge Amado e a narrativa suburbana do moralismo e das transgressões em Nelson Rodrigues. Sônia corporifica, assim, representações distintas da mulher brasileira, quase sempre a partir de um componente erótico:

O poder de encantamento do cinema está precisamente neste encontro: como os corpos convidam os seus espectadores a entrarem no filme, tomam-nos pela mão, levam-nos a passear, como graças a eles, a história se torna "a minha história" para cada um (BAECQUE, 2009, p. 494). 
O sentido de espelhamento entre Clara e Sônia Braga resulta, então, desses elementos variados: a memória contracultural do significante aquarius, as canções no toca-discos, a interpretação naturalista nos momentos de intimidade solitária, tudo isso cria essa espécie de duplo no filme. Vemos em Clara, muitas vezes, a presença de Sônia Braga, não da maneira como costumeiramente se vê o ator no gesto de sua interpretação, mas como a retomada de algum fio discursivo que liga a atriz à memória de subjetividades constituintes de brasilidades que submergem diante da violência das transformações nos modos de vida. É nos momentos de apresentação da intimidade de Clara, sozinha e autônoma em seu espaço vital, que a presença da memória da trajetória da atriz na personagem se faz mais presente. O convite para filmar Aquarius se torna, assim, um ato político, conectando a história da atriz com a da personagem, como ela mesmo traduz em depoimento no lançamento do filme:

O Kleber, quando me mandou o roteiro, ele me conhecia... Ele deu, para cada
momento da minha vida, em 30 e tantos anos, uma palavra. Conforme eu ia lendo,
tudo ia fazendo sentido. E pensar que eu ia poder dizer aquelas palavras, e que
finalmente eu tinha encontrado uma plataforma. Sentia que o roteiro, que começa
nos anos 1980 (no momento que venho pros EUA), dava sentido pra tudo que eu
tinha vivido. Não foi uma oportunidade que o Kleber me deu, mas ele me resgatou,
quase que num ato político. O Kleber criou da minha vida um filme de suspense do
qual você é resgatado no último momento. Eu sinto que pertenço ao Brasil hoje de
uma maneira muito maior (MONETTI, 2016, online).

Assim, a Sônia Braga que vemos em Clara é representativa do movimento dos arquivos de brasilidade (CARVALHO, 2014, 2015). O conceito, já desenvolvido em trabalhos anteriores, passa pela utilização da metodologia arqueológica de Foucault (2010) para a interpretação da história brasileira a partir do ponto de vista discursivo, sobretudo na relação entre acontecimento e memória. A volta da atriz 20 anos depois para interpretar um papel dialógico em relação à sua trajetória, a recepção do filme no momento de tomada de poder de um grupo político retrógrado, a memória de relações mais calorosas e afetivas em contraponto à ordem pragmática do capitalismo do século XXI constituem uma rede de discursos que contribuem para elucidação do atual momento histórico brasileiro no cruzamento entre arte, mercado e política; contexto em que se constitui o cinema de Kleber Mendonça também como discurso de interpretação do Brasil. 


\section{O cinema político de Kleber Mendonça e as (re) invenções do Nordeste}

O elo entre o acontecimento de Aquarius e o momento político brasileiro está na conexão entre o enredo do filme e a trajetória de Sônia Braga: efeito potencializado pelo protesto da equipe no emblemático Festival de Cinema de Cannes, na França. Sônia Braga viu no ato "Uma instalação ao vivo. Aquilo foi um movimento artístico. Foi uma Lygia Clark que surgiu em mim” (MONETTI, 2016, online). A referência à artista plástica que buscou integrar arte e vida (ROLNIK, 2011) aponta para uma das cartografias da contracultura brasileira. É Sônia quem lembra-nos de Lygia Clark, mas poderia ter sido Clara.

$\mathrm{O}$ protesto ganha densidade se contextualizado com a própria temática do filme. A analogia logo enunciada pelo cineasta traça um comparativo entre a Presidenta - que estava sendo obrigada a deixar sua casa - e Clara/ Sônia Braga: a primeira sofrendo as pressões para fazer tombar o seu edifício de memória e a segunda retornando o diálogo com o público brasileiro via cinema depois de duas décadas. Aquarius é também uma interpretação micropolítica das subjetividades que emergiram da resistência dos anos 1960 e que fizeram do seu próprio modo de vida a revolução em prática. É esse fio discursivo que a história retoma.

Uma singularidade narrativa do cinema de Kleber Mendonça no cenário audiovisual brasileiro está na forma como valoriza silêncios, pausas, temporalidades de um ritmo cotidiano cujos desenlaces levam-nos a construções históricas e sociológicas sobre a violência da sociedade nordestina. Em $O$ som ao redor, a vigilância privada de um bairro do Recife revela associações com o Pernambuco dos engenhos:

Relações sociais em que as pessoas atolavam e apodreciam; em que só o patriarca possuía solidez; em que as gerações de senhores de engenho se sucediam, tendo sempre uma massa de empobrecidos escravos para explorar (ALBUQUERQUE JÚNIOR, 2011, p. 116).

A condução do ritmo da história e da direção dos atores foge do tom histriônico ou excessivo, as falas parecem meio tom abaixo do predominante. Há, entretanto, nesse cotidiano, algo além do visível, ecoa nos atos banais a violência desencadeada por fatores históricos, sociais ou psicológicos, como a dona de casa de que comete pequenas perversidades com o cão vizinho ou com as crianças da rua.

É possível estabelecer, ainda, um paralelo com outro momento da história recente do país, em que as temáticas do cinema e do real se cruzaram com tal força. Referimo-nos à Terra em transe, de Glauber Rocha, lançado em 1967, um ano antes do Ato Institucional número 5, que radicalizou a Ditadura Militar no Brasil. Terra em transe dialoga com o 
momento histórico e é uma das forças propulsoras para a criação do tropicalismo musical. O filme de Glauber utiliza linguagem alegórica para acusar os golpes militares na América Latina e em particular no Brasil (XAVIER, 1993). O cenário é a geografia brasileira, paisagens de sertão-mar - opostas ao intimismo dos filmes de Kleber Mendonça. A temática fala dos conflitos e divisões da esquerda que justificaram a implantação das ditaduras num país fictício: Eldorado. Jardel Filho interpreta Paulo Martins, um jornalista de origem oligárquica convertido ao socialismo, mas que se contradiz ao se aproximar de forças políticas conservadoras. Terra em transe não pode ser pensado fora do contexto do período e da divisão das esquerdas diante de um projeto pedagógico socialista de base paternalista.

O Cinema Novo retoma, para Durval Muniz de Albuquerque (2011), a problemática modernista de conhecer e desvendar o Brasil e o faz através de uma linguagem "na qual a postura racionalizante anterior dá lugar a uma visão mágica e mítica do concreto" (ALBUQUERQUE JÚNIOR, 2011, p. 304). O que se propõe é uma atitude paternalista, tentando conscientizar as massas da necessidade de uma revolução socialista, a exemplo de Cuba. Apesar da grande repercussão internacional pelo caráter de inovação estética e de linguagem, o Cinema Novo ficou restrito, no Brasil, a círculos mais intelectuais da classe média, tornando-se mais uma arte "pelo povo" do que propriamente "para o povo". Para Durval Muniz (2011), a escolha do Nordeste como cenário de grande parte da filmografia de Glauber Rocha faz parte dessa estratégia de busca do popular, recorrendo a estruturas narrativas de cordel, entre o real e o sonho, para produzir uma dizibilidade e visibilidade de país.

O cinema de Kleber conserva do Cinema Novo essa vontade de interpretação do país ${ }^{6}$, embora o caminho estético seja oposto. A escolha do cotidiano, tão presente em $O$ som ao redor e em Aquarius, não abre espaço para imagens estereotipadas e nem para o tom excessivo da atuação dos atores sob o estilo de Glauber Rocha, cujos filmes exploram as paisagens externas de sertão-mar, colocando ênfase na geografia. Em Glauber, o ponto de vista parte do macropolítico para o micropolítico; em Kleber, a perspectiva é inversa: toma a dimensão micropolítica como possibilidade de transformação, distanciando-se das grandes bandeiras macropolíticas dos anos 1960, do desejo da revolução socialista que permeia grande parte da produção do Cinema Novo. Não se trata, nesse curto espaço, de traçar um

\footnotetext{
${ }^{6}$ Do Cinema Novo até Central do Brasil (1998), passando por Cidade de Deus (2002), Tropa de Elite 1 e 2, não tem sido incomum o uso do cinema como interpretação do Brasil.
} 
comparativo entre as duas correntes cinematográficas, mas de perceber nessas descontinuidades tanto a influência quanto a retomada de outros pontos de vista.

Ao optar pela abordagem cotidiana e o ritmo mais lento, o cinema de Kleber esconde, ainda, outra ordem, cuja leitura pode ser pensada pela teoria desenvolvida por Suely Rolnik (2011) a partir da obra de Lygia Clark e pelas influências do pensamento de Deleuze e Guattari, sobretudo presentes na ideia do devir, o vir a ser, os possíveis. A vida consiste, nos diz Rolnik (2011), em instituir territórios simbólicos, movidos pelo afeto e desejo, e em abandoná-los quando sujeito e sentido não mais coincidem. Os movimentos se dão num primeiro momento pelo aspecto intuitivo-inconsciente denominado corpo vibrátil, a partir dos quais o sujeito coloca suas representações visíveis e linguísticas (o nomeado). O momento de saturação de um sentido é, retomando Lygia Clark, "um vazio pleno", porque abre caminho para o movimento cartográfico do sujeito.

A sociedade disciplinar procura bloquear esse movimento, instituindo ilusões de identidades fixas ao sujeito. Ao se voltar para o período da Ditadura Militar, Rolnik (2011) estabelece alguns padrões de subjetividade cristalizadas e que continuam a produzir sentido no contemporâneo, como por exemplo “o coronel em nós”, “o hippie em nós”, “o militante em nós". As ditaduras, sejam elas de esquerda ou de direita, promovem um "enrijecimento patológico do princípio identitário" (ROLNIK, 2011, p. 16). A subjetividade hippie é aquela que busca a fuga de estilos de vida estéreis da burguesia, mas se vê diante de dois excessos, aponta-nos a autora: o primeiro é a constante desterritorialização, a desagregação excessiva, a viagem sem volta; o segundo, ao contrário, é o da criação de um território endurecido, uma comunidade de repetição de gestos, trejeitos e procedimentos. Ambos caminhos reveladores de uma ingenuidade de caráter romântico.

Há, porém, uma outra dimensão do aspecto revolucionário introduzido pela contracultura que é, justamente, a capacidade de instituir territórios simbólicos e abandonálos. É algo que se dá a partir da ideia do vazio pleno proposto por Lygia Clark. Sônia Braga não se tornou a sempre hippie de Hair, nem tampouco a mulata sensual de Gabriela ou de Dona flor e seus dois maridos. A sua trajetória parece confirmar essa disposição de seguir a cartografia dos afetos, nos movimentos de ida e volta: "Quando eu vim para os Estados Unidos eu fui ficando [...] Eu não tenho gato, nem passarinho, nem cachorro [...] então eu sou assim, faço o que quero quando quero" (MONETTI, 2016, online).

Sônia, que já foi tantas outras, voltou ao Brasil para ser Clara. A personagem se fixa no seu território, mas o faz a partir de uma série de vivências cartográficas que indicam a 
manutenção da liberdade interior; os movimentos de territorialização e desterritorialização são simbólicos, não necessariamente físicos. É como se a preservação do espaço de memória representasse metonimicamente o elo com essa força revolucionária da contracultura, antes de sua cooptação pela sociedade disciplinar. É o Brasil das canções dos anos 1960 e 1970 que nos legaram traduções profundas em letras e música de nosso lugar no mundo, o Brasil do jornalismo anárquico do Pasquim, do encontro utópico entre jovens urbanos e os pescadores das vilas litorâneas, daqueles que faziam seu rito de iniciação como mochileiros em busca de si mesmo e de um país, do grito feminista que hoje encontra eco entre a juventude. Um Brasil que encontra também em Sônia Braga sua representação.

Buscar esse domínio de memória no momento do golpe à direita que aponta também para a tentativa de rompimento com esse legado, fortalecendo a normatividade disciplinar e o enrijecimento identitário, é tentar preencher com alguma plenitude um vazio que o movimento macropolítico da história nos legou. Foi esse fio discursivo que ligou o protesto em Cannes ao filme de Kleber e ao retorno de Sônia Braga a algum Brasil.

\section{Considerações finais}

Em um cenário fortemente marcado por um golpe parlamentar e pelas rupturas (políticas e sociais) que daí derivam, buscou-se analisar a irrupção de Aquarius, em setembro de 2016, como um ato político e um acontecimento discursivo. Buscou-se demonstrar como em Clara, em Sônia Braga, em Aquarius, está estampada uma resistência de dimensão histórica, política e cultural. Os becos do apartamento de Clara, entre os quais correm as descontinuidades da vida da personagem, fazem emergir todo um domínio de memória que traz à tona os arquivos de brasilidade e sustentam sua emergência na mesma medida em que oferecem espessura histórica à trajetória de Sônia Braga, ou à própria narrativa fílmica. Nessa dimensão, estão imbricados a modernidade e a contracultura, o ideário hippie e a especulação imobiliária: a construção de uma cartografia histórica da brasilidade materializada na articulação entre Clara e seu passado, entre a Sônia Braga dos anos 60 e a Sônia Braga de Kleber Mendonça.

Em Aquarius, Clara é um acontecimento discursivo (PÊCHEUX, 2008) que expõe uma ruptura e uma atualização dos discursos colecionados por Sônia Braga ao longo de sua carreira. De Hair (1969-1972) a Tieta do agreste (1996), há a exposição de um corpo sensual, embalado pelo erotismo que a nossa formação cultural atribuiu, historicamente, ao corpo da 
mulher. Clara vem atualizar a trajetória da atriz fazendo emergir um discurso mais político e menos erótico, mais ligado ao plano da resistência ou do feminismo e menos ligado ao plano da sensualidade. Prova desse aspecto é a postura da personagem diante do fato de ter perdido um dos seios em virtude de um câncer de mama. Não há, em Clara, um pesar relacionado a seu corpo, há resistência. Resistência que, aliás, muito nos diz em termos políticos, tendo em vista não apenas a doença também enfrentada por Dilma Rousseff, mas principalmente a recusa da presidenta em fazer do câncer (ou das torturas sofridas durante a Ditadura Militar) um pretexto de autocompaixão.

Assim, de todos os ângulos dos quais é possível assistir a Aquarius, estará em jogo o caráter interpretativo do país e mais precisamente de seu cenário político, tão presente no cinema desenvolvido por Kleber Mendonça, herança do Cinema Novo. O filme é uma metonímia do país, um modo de traduzi-lo a partir de seus espaços de memória, com os pés fincados em uma micropolítica que não abre mão de seu passado, de sua dimensão histórica, diante da missão de constituir-se em um presente movediço. É no caráter intimista da micropolítica que o filme se expande, lançando luz a aspectos alegóricos de nossa brasilidade.

À janela de Aquarius, enquanto o capital bate à porta, Clara escuta Taiguara e resiste. Poderia também ser Sônia Braga, num momento de retomada de sua trajetória e de seu retorno, 20 anos além. Poderia, na verdade, ser qualquer um de nós, na nostalgia do que fomos e do que somos (enquanto povo, enquanto país), diante de um cenário que nos solapa cotidianamente: Hoje/ Trago em meu corpo as marcas do meu tempo/ Meu desespero, a vida num momento/ A fossa, a fome, a flor, o fim do mundo...

\section{Referências}

ALBUQUERQUE JÚNIOR, D. M. A invenção do Nordeste e outras artes. São Paulo: Cortez, 2011.

AQUARIUS. Direção de Kleber Mendonça. Produção de Emilie Lesclaux, Saïd Ben Saïd e Michel Merkt. Pernambuco: CinemaScópio Produções, 2016. Blu-Ray.

BAECQUE, A. de. O corpo no cinema. In: CORBIN, A.; COURTINE, J-J.; VIGARELLO, G. História do corpo, vol. 3. As mutações do olhar: o século XX. Petrópolis: Vozes, 2009. p. 481-507.

CARVALHO, P. H. V. de. Revista Piauí: acontecimento no arquivo de brasilidade. Aracaju: EdUNIT, 2014. 
. A voz que canta na voz que fala: poética e política na trajetória de Gilberto Gil.

Cotia, SP: Atelier Editorial, 2015.

CUNHA, I. F. A revolução da Gabriela: o ano de 1977 em Portugal. Cadernos Pagu, Campinas, n. 21, p. 39-73, 2003. Disponível em:

<http://www.scielo.br/pdf/cpa/n21/n21a04.pdf>. Acesso em: 31 mar. 2017.

DAMA do lotação. Adaptação do conto homônimo de Nelson Rodrigues. Direção de Neville d'Almeida. Produção de Alberto Fonseca. Rio de Janeiro: Canal Brasil, 1978. VHS.

DANCIN'DAYS. Escrita por Gilberto Braga. Direção de Daniel Filho. Rio de Janeiro: Rede Globo de Televisão, 1978.

DELEUZE, G.; GUATTARI, F. Mil platôs: capitalismo e esquizofrenia. Rio de Janeiro: Editora 34, 1997.

DONA flor e seus dois maridos. Adaptação do Romance homônimo de Jorge Amado. Direção de Bruno Barreto. Produção de Luiz Carlos Barreto. Bahia: Carnaval Unifilm; Coline; Companhia Cinematográfica Serrador; LC Barreto Produções Cinematográficas, 1976. VHS.

EL PAIS Brasil. Equipe de 'Aquarius', de Kleber Mendonça Filho, protesta em Cannes. 19 maio 2016. Disponível em: 〈http://brasil.elpais.com/brasil/2016/05/17/cultura/1463498064_139719.html〉. Acesso em: 27 mar. 2017.

EU te amo. Adaptação do romance homônimo de Arnaldo Jabor. Direção de Arnaldo Jabor. Produção de Walter Clark. Rio de Janeiro: Flávia Filmes, 1981. VHS.

DAMATTA. R. O que faz o brasil, Brasil? Rio de Janeiro: Rocco, 1986.

DIAS, L. Anos 70: enquanto corria a barca. São Paulo: Senac, 2003.

FERREIRA, F. Sónia Braga: “Pra mim, ‘Aquarius’ é o Brasil”. Expresso, 25 mar. 2017. Disponível em: <http://expresso.sapo.pt/cultura/2017-03-25-Sonia-Braga-Para-mimAquarius-e-o-Brasil >. Acesso em 27 mar. 2017.

FOUCAULT, M. Outros espaços. In: Ditos e escritos III. Estética: Literatura e pintura, música e cinema. Rio de Janeiro: Forense Universitária, 2003. p.411-422.

. A arqueologia do saber. Tradução de Luiz Felipe Baeta Neves. 7. ed. Rio de Janeiro: Forense Universitária, 2010.

Vigiar e punir: nascimento da prisão. Tradução de Raquel Ramalhete. 41. ed. Petrópolis: Vozes, 2013.

FREYRE, G. Casa-grande \& senzala: formação da família brasileira sob o regime da economia patriarcal (Introdução à história da sociedade patriarcal no Brasil - 1). 51 ed. rev. São Paulo: Global, 2006.

GABRIELA. Adaptação do Romance Gabriela, cravo e canela, de Jorge Amado. Escrita por Walter George Durst. Direção de Walter Avancini e Gonzaga Blota. Bahia: Rede Globo de Televisão, 1975. VHS. 
GOMES, K. A vingança de Aquarius sobre a realidade política brasileira. Publico, 17 mar. 2017. Disponível em: <https://www.publico.pt/2017/03/17/culturaipsilon/noticia/a-vingancade-aquarius-sobre-a-realidade-politica-brasileira-1765275>. Acesso em 27 mar. 2017.

GUATTARI, F.; ROLNIK, S. Micropolítica: cartografias do desejo. 4. ed. Petrópolis: Vozes, 1996.

HAIR. Adaptação do musical americano Hair: The American Tribal Love-Rock Musical, escrito por James Rado e Gerome Ragni. Direção de Admar Guerra. Produção de Altair Lima. São Paulo. 1969-1972. Musical.

MENDES, M. Sônia Braga, uma ideia de país. Publico, 17 mar. 2017. Disponível em: <https://www.publico.pt/2017/03/17/culturaipsilon/noticia/ela-1765020>. Acessado em: 31 mar. 2017.

MONETTI, Tino. "Estou inteirinha lá": uma entrevista com Sônia Braga sobre "Aquarius". Vice, 25 ago. 2016. Disponível em: <https://www.vice.com/pt_br/article/sonia-bragaentrevista-2016>._Acesso em: 04 abri. 2017.

O SOM ao redor. Direção de Kleber Mendonça. Produção de Emilie Lesclaux. Pernambuco: CinemaScópio, 2012. Blu-Ray.

PÊCHEUX, M. O discurso: estrutura ou acontecimento. Tradução de Eni P. Orlandi. 5 ed. Pontes: Campinas, 2008.

ROLNIK, S. Políticas da hibridização: evitando falsos problemas. In: LIMA, E. A.; FERREIRA NETO, J. L.; ARAGON, L. E. (org.). Subjetividades contemporâneas: desafios teóricos e metodológicos. Curitiba: CRV, 2010. p.15-25.

Cartografia sentimental. Porto Alegre: Sulina/Editora UGRGS, 2011.

SIMÕES, I. F.; COSTA, A. H.; KEHL, M. R. Um país no ar: história da TV brasileira em três canais. Brasiliense: São Paulo, 1986.

TERRA em transe. Direção de Glauber Rocha. Rio de Janeiro: Mapa Produções Cinematográficas, 1967. VHS.

TIETA do Agreste. Adaptação do romance homônimo de Jorge Amado. Direção de Cacá Diegues. Produção de Bruno Stroppiana e Donald Ranvaud. Rio Grande do Norte: Sky Light Cinema; Films Vintage, 1996. VHS.

VALEK, A. Aquarius: a resistência é um lugar solitário. Carta Capital, 14 set. 2016. Disponível em: <https://www.cartacapital.com.br/cultura/aquarius-a-resistencia-e-um-lugarsolitario>. Acesso em: 27 mar. 2017.

XAVIER, I. Alegorias do subdesenvolvimento: Cinema Novo, tropicalismo, Cinema Marginal. São Paulo: Brasiliense, 1993.

Recebido em 11/06/2018 Aceito para publicação em: 26/07/2018 